\title{
Syn-eruptive, soft-sediment deformation of deposits from dilute pyroclastic density current: triggers from granular shear, dynamic pore pressure, ballistic impacts and shock waves
}

\author{
G. A. Douillet ${ }^{1}$, B. Taisne ${ }^{2}$, È. Tsang-Hin-Sun ${ }^{3}$, S. K. Müller ${ }^{4}$, U. Kueppers ${ }^{1}$, and D. B. Dingwell ${ }^{1}$ \\ ${ }^{1}$ Earth and Environmental Sciences, Ludwig-Maximilians-Universität, Munich, Germany \\ ${ }^{2}$ Earth Observatory of Singapore, Nanyang Technological University, Singapore \\ ${ }^{3}$ Université of Brest and CNRS, Laboratoire Domaines Océaniques, Plouzaré, France \\ ${ }^{4}$ Meteorological Institute, Ludwig-Maximilians-Universität, Munich, Germany
}

Correspondence to: G. A. Douillet (g.douillet@min.uni-muenchen.de)

Received: 17 November 2014 - Published in Solid Earth Discuss.: 16 December 2014

Revised: 16 April 2015 - Accepted: 20 April 2015 - Published: 21 May 2015

\begin{abstract}
Soft-sediment deformation structures can provide valuable information about the conditions of parent flows, the sediment state and the surrounding environment. Here, examples of soft-sediment deformation in deposits of dilute pyroclastic density currents are documented and possible syn-eruptive triggers suggested. Outcrops from six different volcanoes have been compiled in order to provide a broad perspective on the variety of structures: Soufrière Hills (Montserrat), Tungurahua (Ecuador), Ubehebe craters (USA), Laacher See (Germany), and Tower Hill and Purrumbete lakes (both Australia).

The variety of features can be classified in four groups: (1) tubular features such as pipes; (2) isolated, laterally oriented deformation such as overturned or oversteepened laminations and vortex-shaped laminae; (3) folds-and-faults structures involving thick (>30 cm) units; (4) dominantly vertical inter-penetration of two layers such as potatoids, dishes, or diapiric flame-like structures.

The occurrence of degassing pipes together with basal intrusions suggest fluidization during flow stages, and can facilitate the development of other soft-sediment deformation structures. Variations from injection dikes to suction-driven, local uplifts at the base of outcrops indicate the role of dynamic pore pressure. Isolated, centimeter-scale, overturned beds with vortex forms have been interpreted
\end{abstract}

to be the signature of shear instabilities occurring at the boundary of two granular media. They may represent the frozen record of granular, pseudo Kelvin-Helmholtz instabilities. Their recognition can be a diagnostic for flows with a granular basal boundary layer. Vertical inter-penetration and those folds-and-faults features related to slumps are driven by their excess weight and occur after deposition but penecontemporaneous to the eruption. The passage of shock waves emanating from the vent may also produce trains of isolated, fine-grained overturned beds that disturb the surface bedding without occurrence of a sedimentation phase in the vicinity of explosion centers. Finally, ballistic impacts can trigger unconventional sags producing local displacement or liquefaction. Based on the deformation depth, these can yield precise insights into depositional unit boundaries. Such impact structures may also be at the origin of some of the steep truncation planes visible at the base of the so-called "chute and pool" structures.

Dilute pyroclastic density currents occur contemporaneously with seismogenic volcanic explosions. They can experience extremely high sedimentation rates and may flow at the border between traction, granular and fluid-escape boundary zones. They are often deposited on steep slopes and can incorporate large amounts of water and gas in the 
sediment. These are just some of the many possible triggers acting in a single environment, and they reveal the potential for insights into the eruptive and flow mechanisms of dilute pyroclastic density currents.

\section{Introduction}

The dynamics of pyroclastic density currents (PDCs) remain poorly understood. This is despite the fact that they are one of the most efficient transport means on the flanks of volcanoes exhibiting explosive eruptions, thereby yielding a major risk potential for life, environment and infrastructures. Analogue and numerical modeling approaches are well-suited to investigate targeted hypothesized processes, but the question of which process to model can only be answered through real PDC data. Cross-bedded, dilute PDC deposits can contain intriguing overturned and deformed patterns attributed to soft-sediment deformation (SSD). The understanding of these structures can yield insight into the syn- and postdepositional processes surrounding the bed interface: i.e., the basal boundary layer (BBL), the bed state, and conditions extant in the emplacement environment. In particular, syn-depositional SSD structures provide constraint on the shearing and dynamic pore pressure at the BBL that controls the sedimentation of PDCs, whereas syn-eruptive SSD records information on the eruptive dynamics and depositional units. PDCs are largely emplaced subaerially under metastable deposition state favoring SSD. Thus a variety of specific SSD triggers may occur during an eruption and PDC deposits represent excellent targets for studies of SSD.

\subsection{Soft-sediment deformation}

Occasionally, stratified sediments exhibit anomalous patterns that cannot be explained by simple depositional schemes, and are understood as soft-sediment deformation (SSD) i.e., changes in the initial bed structure. This occurs during or shortly after deposition and prior to consequent diagenesis (Van Loon, 2009; Owen et al., 2011). SSD has been documented for subaqueous clastic sediments from the mud to coarse sand range (Van Loon, 2009; Owen and Moretti, 2011), including turbidites (Moretti et al., 2001), subglacial environments (Ghienne, 2003; Denis et al., 2010; Douillet et al., 2012; Pisarska-Jamroży and Weckwerth, 2013), carbonates (Ettensohn et al., 2011; Chen and Lee, 2013), and volcanic ash (Gibert et al., 2011). In subaerial environments, SSD is documented from earthquake-triggered liquefaction and can form sand blows and dykes.

A variety of triggers can be involved (Owen and Moretti, 2011), generally predominantly related to seismically induced liquefaction (Sediment. Geol. 235, Nichols et al., 1994; Mohindra and Bagati, 1996; Owen, 1996b; Owen and Moretti, 2011), but also to tsunami waves (Alsop and Marco,
2012), storms (Chen and Lee, 2013) or volcanic base surges (Crowe and Fisher, 1973).

\subsubsection{Nomenclature}

There is neither a single classification scheme nor agreement on the nomenclature of SSD patterns (e.g., Lowe, 1975; Owen, 1987; Van Loon, 2009; Owen et al., 2011). Here, a non-generic nomenclature based on descriptive characteristics is employed.

Pipes: masses of sediments having different characteristics compared to the surrounding unit and with a relatively tubular shape. Used here as a generic descriptive umbrella term for structures such as dikes or pillars (e.g., Mills, 1983; Nichols et al., 1994; Owen, 2003; Owen and Moretti, 2008; Douillet et al., 2012). Degassing (or de-watering) structures or injection dikes are interpretative terms of pipes.

Overturned laminae/beds and vortex bedding: a few laminations or layers that show a coherent recumbent overturning, generally aligned with the parent flow direction given by nearby sedimentary structures. They are laterally confined in otherwise undisturbed bedding. They can occur in sets of downstream repetitive but isolated patterns. They are distinct from overturned stratification, which is an overturning of a stratal package as a whole (Allen and Banks, 1972; Røe and Hermansen, 2006; Bridge and Demicco, 2008, p. 357-358). Vortex lamination/bedding is similar as overturned laminae/beds, but with a vortex shape (Rowley et al., 2011). "Vorticity" is preferred to "rotation" here and throughout since any simple shear deformation includes a rotational component.

Folds-and-faults structures: units involving several beds showing folding as well as discontinuities (microfaults) leading to concatenation (overlap). The general organization tends toward overturning with a coherent orientation (e.g., Odonne et al., 2011; Alsop and Marco, 2011). The term "slumped beds" is avoided because of its interpretative sense.

Potatoids, dishes and diapiric flame-like structures: result from the movement of two layers of significantly different characteristics (densities, grain size) that penetrate into each others. Potatoids result of dominantly vertical movement forming deformations with irregular rounded shapes. They are generally massive. Attached/detached potatoid is used to emphasize whether the intrusive body is still connected to the layer it initially belonged to or not (e.g., Owen, 1996a). Dishes are thin and tabular detached masses. Diapiric flame-like structures are laterally persistent deformation patches destroying the initial bedding. They have no coherent recumbence and dominantly vertical patterns (Crowe and Fisher, 1973; Owen, 1996b; Niebling et al., 2010). They are distinguished from convolute/contorted bedding, the latter preserving the original bed set succession (Owen et al., 2011). Terms such as load-casts or pseudo nodules are avoided here since they contain an interpretation on their formation. 
The interpretation of the trigger mechanism(s) for SSD is not always straightforward and can include a combination of different effects. Here, distinction is made between the deformation, the agent of deformation, and the trigger. The deformation tensor in rock mechanics can be written as a sum of components of stretching, pure shear and simple shear (rotation). Identification of the relationships with the surroundings permits the interpretation of the physical agents responsible for the deformation as well as possible triggers.

Of interest here is the distinction between (1) synsedimentary BBL (flow) shearing and dynamic pore pressure effects, (2) intra-deposit movements, and (3) post depositional mass movements. Bioturbation and biochemical effects are not dealt with here. BBL shearing includes the effects of the flow drag during or directly after sedimentation. It can be enhanced by the sediment state and the nature of the BBL. Intra-deposit movements lead to sediment fabric rearrangement and deformation. These are often related to the expelling of trapped fluids during or after sedimentation, in situ releases, or compaction and loading. Mass movements are understood here as slumping, i.e., a short-scale, rather coherent sediment re-mobilization, the limit of which is taken to be debris flows. At the origin of the deformation, a trigger can occur - a phenomenon that is not directly described in terms of the forces producing the deformation, but is causally responsible for their generation (e.g., ground-shaking facilitating liquefaction of sediment, favoring fluid movements and producing ball-and-pillow structures).

\subsection{PDCs and their possible SSD triggers}

As particulate density currents, the depositional processes of PDCs are fundamental in their dynamics, since particles are both the agent of excess density driving momentum and the resulting sediment. Extreme and varied flow-substrate BBL processes may occur. The classification of Branney and Kokelaar (2002) emphasizes BBL processes and theorizes a classification into four end-member types: granular-, fluid-escape-, fallout-, and traction-dominated BBLs. Douillet et al. (2014) discussed different types of cross-bedding aggradation patterns as an upper or lower limit of the saltation threshold (the minimum shearing required to put grains in motion by wind), thus supposing a tractional BBL scheme. Alternatively, emplacement can be envisioned as a series of pulses with high basal concentration and no relationship to saltation, regardless of averaged concentration (Doronzo and Dellino, 2014), or stepwise en-masse deposition (Sulpizio and Dellino, 2008). The understanding of the nature and significance of BBL processes for PDCs may be further augmented by the study of syn-depositional SSD.

PDC deposits often display SSD (also "soft-state deformation”, Branney and Kokelaar, 1994, 2002). This may be associated with subaqueous eruptions (Fiske, 1963) or subaqueous deposition (Brand and White, 2007; Brand and Clarke, 2009; Jordan et al., 2013), but also importantly, subaerial emplacement (Vazquez and Ort, 2006). Hot-state, plastic deformation including partial deformation of the clasts themselves is referred to as rheomorphism (Branney et al., 2004; Andrews and Branney, 2011). Lava flows may also deform underlying soft-sediment beds (Rawcliffe and Brown, 2014). The high sedimentation rate characteristic of particulate density currents results in metastable deposits prone to further re-arrangement (Smith and Kokelaar, 2013). Moreover, the variations from very fine to very coarse beds typical of pyroclastic deposits as well as common inverse grading make them susceptible to SSD after deposition (Gibert et al., 2011).

In addition to their metastable nature, the eruptive environment itself is subject to a variety of triggers. Seismic activity associated with eruption further destabilizes freshly emplaced pyroclasts. Syn-PDC processes can be recorded in SSD (Crowe and Fisher, 1973), and the likely formation of traction carpets and granular BBL can produce granular shear instabilities (Rowley, 2010; Rowley et al., 2011; Smith and Kokelaar, 2013). "Flame-like" structures are often reported (McDonough et al., 1984; Valentine et al., 1989; Brand and White, 2007; Brand and Clarke, 2009) and when interpreted as sheared structures, can serve to reconstruct paleo-flow directions (Giannetti and Luongo, 1994; Brown et al., 2008). Fluid escape SSD (dikes, pipes, plumes, pillars) can occur by escape of water accompanying phreatomagmatic eruptions (Nocita, 1988, -later reinterpreted as water-escape in fluvial deposits by McPherson et al. (1989)), degassing of fresh pyroclasts (Gernon et al., 2008, 2009), burning underlying vegetation, or be due to thermal expansion (Branney and Kokelaar, 2002, p. 61-66, and references therein). Interestingly, the high deposition rates combined with possible fluidized state of the flow can trap gases in the deposits that subsequently escape as degassing pipes within seconds after deposition (Komorowski et al., 2013). These can occur as fines-depleted pipes, a few centimeters in length and diameter (Pistolesi et al., 2011; Smith and Kokelaar, 2013), or large decimeter-meter scale depressions at the surface of deposits (Charbonnier and Gertisser, 2008). The high deposition rates also trigger simple load casts (Mattsson and Tripoli, 2011). Blocks ejected ballistically during an eruptive event deform the fresh deposits by landing (Gençalioğlu-Kuşcu et al., 2007; Jordan et al., 2013). Post eruptive processes are also common on steep sided volcanic edifices, with freshly deposited material likely to be unstable and slump (Fiske and Tobisch, 1978; Voight et al., 1983; Branney and Kokelaar, 1994; Ward and Day, 2006) as well as inherent contraction and compaction fractures following emplacement (Whelley et al., 2012). 


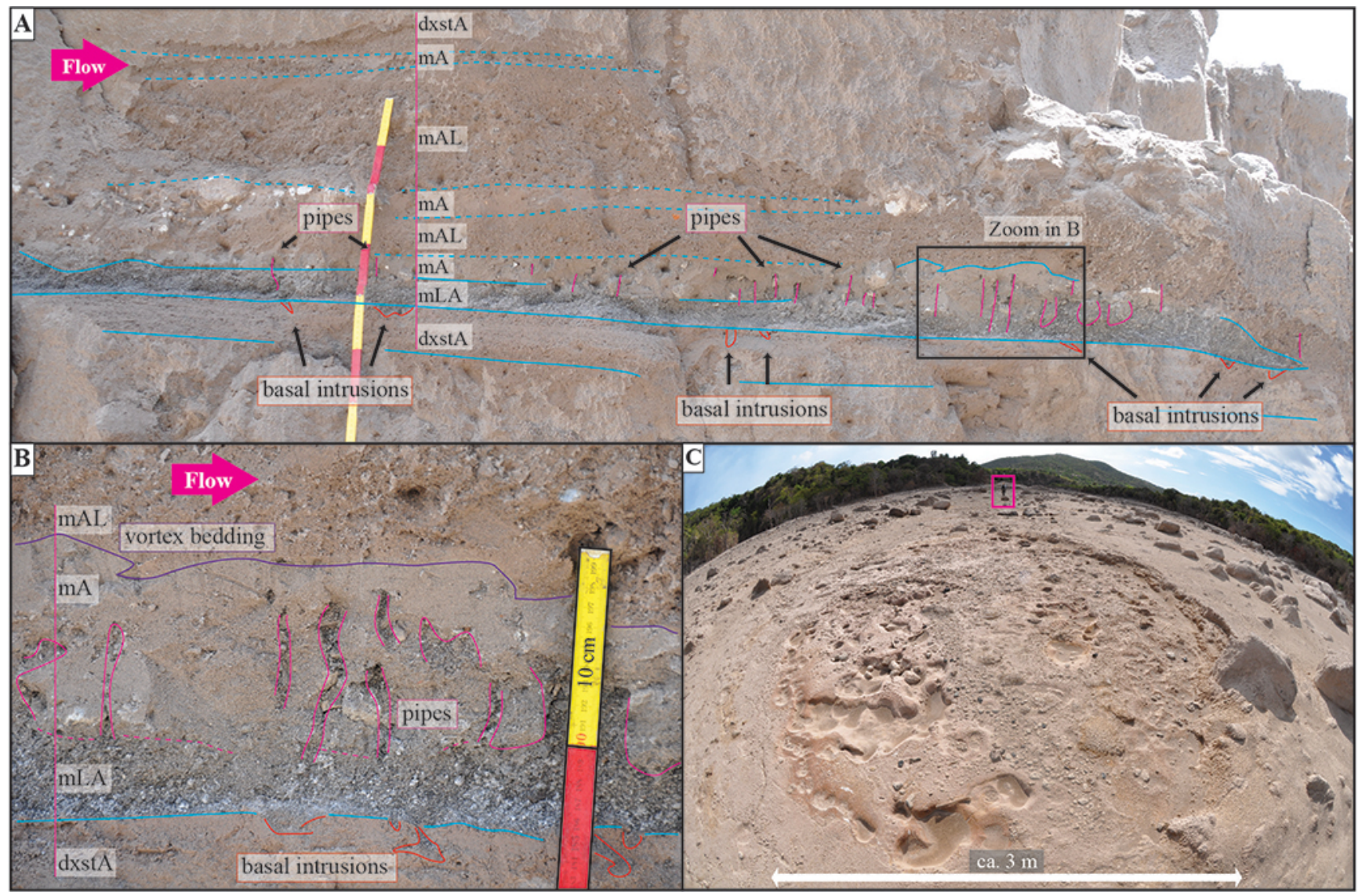

Figure 1. SSD from the 2010 dome collapse PDC deposits at Soufrière Hills in the Belham valley. (a) Degassing pipes occur in a massive ash (mA) layer, and seem to emanate from the underlying massive lapilli and ash layer (mLA). The base of the mLA layer also exhibits basal intrusions of small pipes, and attached potatoids in the underlying diffusely cross-stratified ash bed sets (dxstA). (b) Zoom in SSD structures. The upper contact is uneven with a vortex and undulating form. (c) Large-scale, circular depression, ca. $10 \mathrm{~cm}$ in throw. Note also smaller-scale structures within the main depression.

\subsection{Granular shear instabilities}

Observations of syn-flow shear structures bring further insights into the BBL processes of PDCs. Simple shear is often invoked for the formation of overturned stratification (e.g., Allen and Banks, 1972; Mills, 1983; Røe and Hermansen, 2006). For such structures, the flow transmits and imposes part of its shear stress to the ground and thus translates the uppermost beds. In the other hand, shear instabilities can be produced at the boundary between two fluids to form recurrent, vortex-shaped, Kelvin-Helmholtz instabilities. Valentine et al. (1989) suggested that flame-like SSD structures could be related to Kelvin-Helmholtz instabilities "between the bed load fluid and the overlying surge". Several analogue experimental studies with granular flows over grain beds have evidenced isolated but recurrent wave-like instabilities at the bed-flow interface (Goldfarb et al., 2002; Mangeney et al., 2010; Rowley, 2010; Roche et al., 2013; Farin et al., 2014). Goldfarb et al. (2002) have produced trains of wave instabilities with the shape of overturned laminae and noted that those were "likely produced by shearing differences" and "lacked any kind of vorticity". However, a rotational component must be present to produce the observed shark fin patterns. Rowley (2010) and Rowley et al. (2011) have imaged trains of shear instabilities with well-developed vortex bedding, convincingly interpreted as granular Kelvin-Helmholz instabilities. They further demonstrate the periodicity of these structures and document field examples. The wavy nature of those instabilities was further demonstrated in Farin et al. (2014), which also noted that the wavelength and amplitude are greatest for slopes close to the repose angle (highest speed). Roche et al. (2013) provided videos of the instabilities and an explanation for the fluid-like behavior of these instabilities. They suggested as a mechanism that negative dynamic pore pressures fluidize fine-grained beds and deform them as a whole rather than as individual grains. Other experimental work with granular flows has evidenced intriguing inter-penetration of beds over sinusoidal surfaces (Caicedo-Carvajal et al., 2006), longitudinal vortices in the 
flow direction (Forterre and Pouliquen, 2001), or Taylor vortices (Conway et al., 2004).

\section{Geological settings and occurrence of SSD structures}

The SSD structures presented here belong to different volcanoes and both magmatic and phreatomagmatic eruptions of various intensities and depositional environments. As pointed by Mills (1983), SSD should be studied within their environment, and thus a brief context is introduced. Several types of SSD are identified with orders of magnitude between their dimensions as well as between the grain size of layers involved. Description of all discussed SSD structures is presented in Table 1.

\subsection{Soufrière Hills (Montserrat)}

The 11 February 2010 partial dome-collapse event of Soufrière Hills (Montserrat) produced a series of six block and ash flows, five of them occurring within $15 \mathrm{~min}$, and was the largest event since the 1995 awakening (Wadge et al., 2014; Stinton et al., 2014). Numerous degassing pipes were observed in block and ash flow deposits as well as massive ash units (Stinton et al., 2014). Other post-depositional structures are described by Stinton et al. (2014) as "rootless phreatic explosion craters", i.e., structures related to hot blocks turning water into steam explosively. They can have diameters between 1 and $30 \mathrm{~m}$, consist of "decimeter-sized blocks in a coarse ash-rich matrix derived from the underlying primary PDC deposits" and have a contact to underlying cross-bedded units or down to the pre-collapse surface. Here, SSD structures are documented from the Belham river valley less than $6 \mathrm{~km}$ from the vent (Fig. 1). According to Stinton et al. (2014), only three PDCs flowed in this drainage (stage 3-H, 4-K and 4-6), Wadge et al. (2014) also mentioning PDCs in this zone for the 11 February 2010 collapse. Basal, small-scale pipes and attached potatoids intrude underlying diffusely cross-stratified ash from a massive lapilli-and-ash lens, whereas fines-poor, small-scale pipes are found in the otherwise ash-rich, massive, overlying layer (Fig. 1a-b). The top of the latter has a contact with a series of three vortex and undulating forms (Fig. 1b). These deposits are found in the thalweg of the river valley, which may have contained some water. Another outcrop exhibits a large scale circular depression (ca. $3 \mathrm{~m}$ diam.) with ca. $10 \mathrm{~cm}$ deflation at the surface of the deposits (Fig. 1c).

\subsection{Tungurahua (Ecuador)}

The 17 August 2006 PDCs (Kelfoun et al., 2009; Douillet et al., 2013b; Hall et al., 2013; Bernard et al., 2014) are not linked to phreatomagmatic processes but rather to accumulation and subsequent destabilization of pyroclasts near the crater. The overbank sediments containing the SSD structures have been interpreted to have formed from dilute PDCs originating from dense PDCs by flow stripping (Douillet et al., 2013b). SSD was identified in a lacquer peel within well-developed millimeter-scale ash lamination (Fig. 2) located on the lee side (approx. $20 \mathrm{~cm}$ from the crest) of an aggrading, transverse dune bedform that indicated very high sedimentation rates (Douillet et al., 2013a) approx. $6 \mathrm{~km}$ from the vent. Two clusters of small-scale overturned and recumbent laminae occur at different height in the same horizons. The upper structure exhibits a single, well-developed overturned laminaset (Fig. 2b), whereas the lower one is a cluster of several recumbent overturned laminae forming a front followed by relatively massive material with diffuse oversteepened bedding in the upstream direction (Fig. 2c-d).

\subsection{Ubehebe crater (California, USA)}

Ubehebe tuff ring is part of the Holocene/Pleistocene Ubehebe Craters complex and may have erupted between 0.8 and $2.1 \mathrm{ka}$ (Sasnett et al., 2012). They erupted onto ancient lake sediments, at least partially phreatomagmatically. The arid climate does not explain the phreatomagmatic activity and interaction with a shallow water table is preferred (Sasnett et al., 2012). Crowe and Fisher (1973) reported SSD structures such as contorted beds without preferred orientation, flame structures oriented with the flow direction and disrupted layers of thin tuff curled and pulled apart. They mapped the orientation of ballistic impact sags, mention post-eruption slumping on the northwestern and southeastern parts of the crater, and noted that SSD occurs within pre-existing channels filled with massive deposits but is absent in cross-bedded dominated overbanks. Here, a variety of SSD structures are documented from the southern flank: folds-and-faults, curled dishes, SSD from ballistic impact sags, a diapiric flame-like horizon and vortex features (Fig. 3).

\subsection{Laacher See (Germany)}

Laacher See was the location of a large eruption commonly attributed to phreatomagmatic explosions around 11800 yrs B.P. (Schmincke et al., 1973). Dune bedforms cross-stratification made of coarse lapilli to fine ash intercalated with lapilli to volcanic dust fall horizons occur over tens of square kilometers. Three isolated SSD structures are found around the Wingertsbergwand area, several kilometers southward from the inferred vents (Fig. 4). A composite SSD structure several meters long and ca. $1 \mathrm{~m}$ thick occurs as a lateral series of tilted blocks that evolve into folds-and-faults beds in the (approximate) downstream direction, accommodating a local compression (Fig. 4a-f). It is abruptly confined in depth by the lower ash layer and underlying beds show no sign of deformation. A few tens of meters distant, a structure of similar dimensions characterized by very steep lamination and downward 


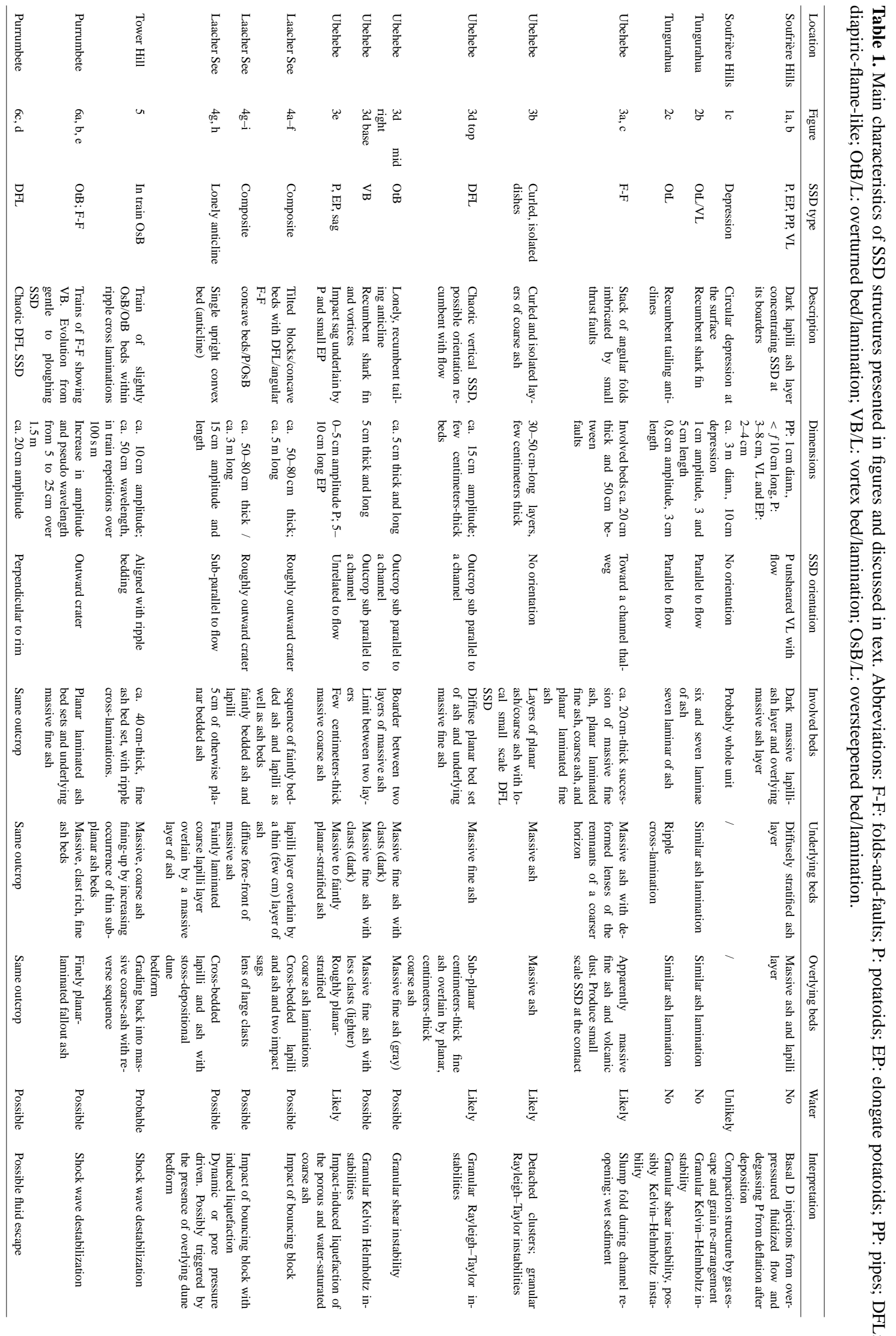



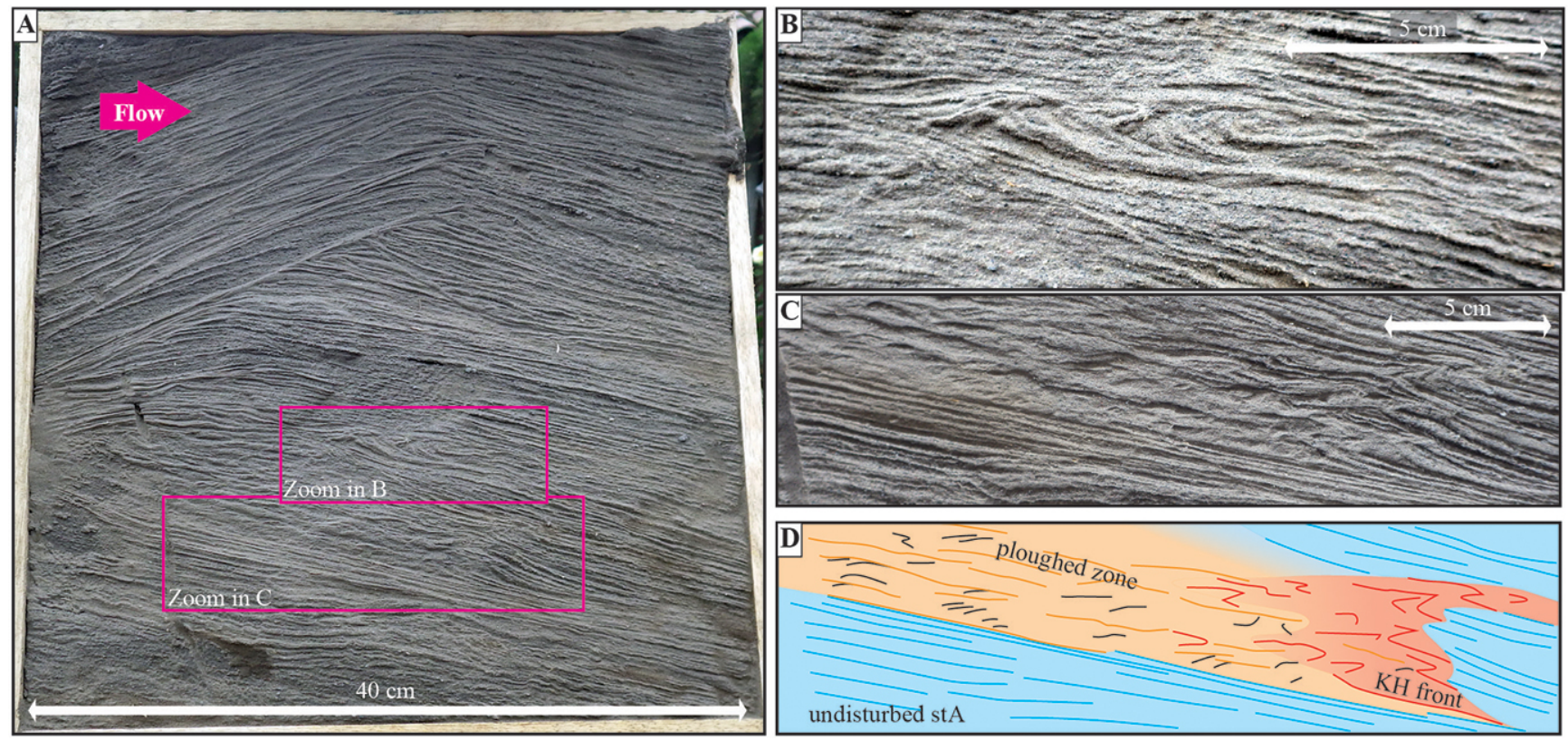

Figure 2. Overturned laminations from Tungurahua in the Achupashal valley (see Douillet et al., 2013a) illustrating shear in a granular BBL (imprint from lacquer peel). (a) Peel showing stoss-depositional ash bed sets, insets highlight the borders of (b) and (c). (b) Imbricated, downflow-recumbent, vortex-shaped SSD structure. Panels (c) and (d) show recumbent and tailing overturned laminae form a front of deformation. The zone upstream the front contrasts with the downstream undisturbed bedding: it is comparatively massive, with thick beds and diffuse oversteepened stratification attributed to the ploughing effect of the downstream moving shear instabilities from the deformation front.

oriented, massive, lapilli potatoids resembles a "chute and pool" structure (Fig. 4g-i). A further structure, approx. $150 \mathrm{~m}$ away, has a convex symmetrical form (ca. $10 \mathrm{~cm}$ vertical displacement) in an initially planar fine-grained bed. It is intercalated above a massive ash bed and below coarse-ash to lapilli, sub-planar, diffuse bed sets (Fig. 4j-k). Flow direction inferred from overlying cross beds is roughly oriented from left to right but may be sub-parallel to the outcrop wall. The bed is partly missing on the right from the deformation. Similar ash layers pinch out above the convex shape and may represent an overlap of the same unit.

\subsection{Tower Hill (Victoria, Australia)}

Tower Hill maar (ca. 35000 yrs B.P., Sherwood et al., 2004; Prata and Cas, 2012) exhibits intriguing trains of oversteepened laminations contained within a single bed set (Fig. 5). They outcrop in the upper part of the Southern rim (CRB quarry), parallel to the crater wall. Underlying beds fine up from massive coarse ash and lapilli by increasing occurrence of thin, sub-planar, ash beds forming a diffusely stratified lapilli-ash facies. This grades into the fine-grained ripple beds with topping SSD and the reverse sequence occurs above. This sequence suggests a fall phase progressively influenced by pseudo base surges (in the sense of Waters and Fisher, 1971) with increasingly efficient fragmentation related to phreatomagmatic explosions at the fine-grained SSD bed sets (optimally efficient water:magma ratio in Prata, 2012). The flow direction inferred from the underlying ripple bedding is oriented roughly parallel to the lateral extension of the outcrop (Prata, 2012). The SSD consists of isolated, oversteepened laminations with coherent orientation. They are recurrent with wavelength of ca. $50 \mathrm{~cm}$ and over hundreds of $\mathrm{m}$.

\subsection{Purrumbete Lake (Victoria, Australia)}

The deposits forming the Purrumbete maar (ca. 20000 yrs B.P.) are characterized by three temporally separated eruption phases and vent locations, with relatively dry as well as wet phreatomagmatic conditions (Jordan et al., 2013). Ballistic bombs with impact sags are widespread in these deposits, suggesting wet deposits (Jordan et al., 2013). The SSD documented here outcrops with two faces at right angles. Perpendicular to the crater, folds-and-faults structures increase in size, faulting and recumbence outward from the vent and seem to have a recurrence and increasing wavelength (Fig. 6a-b, e). Parallel to the rim, only chaotic flame-like structures are visible (Fig. 6c-d). The overlying deposits are planar laminated ash with individual laminae followed over several meters. They lie conformably on the SSD horizon and are related to fallout. 

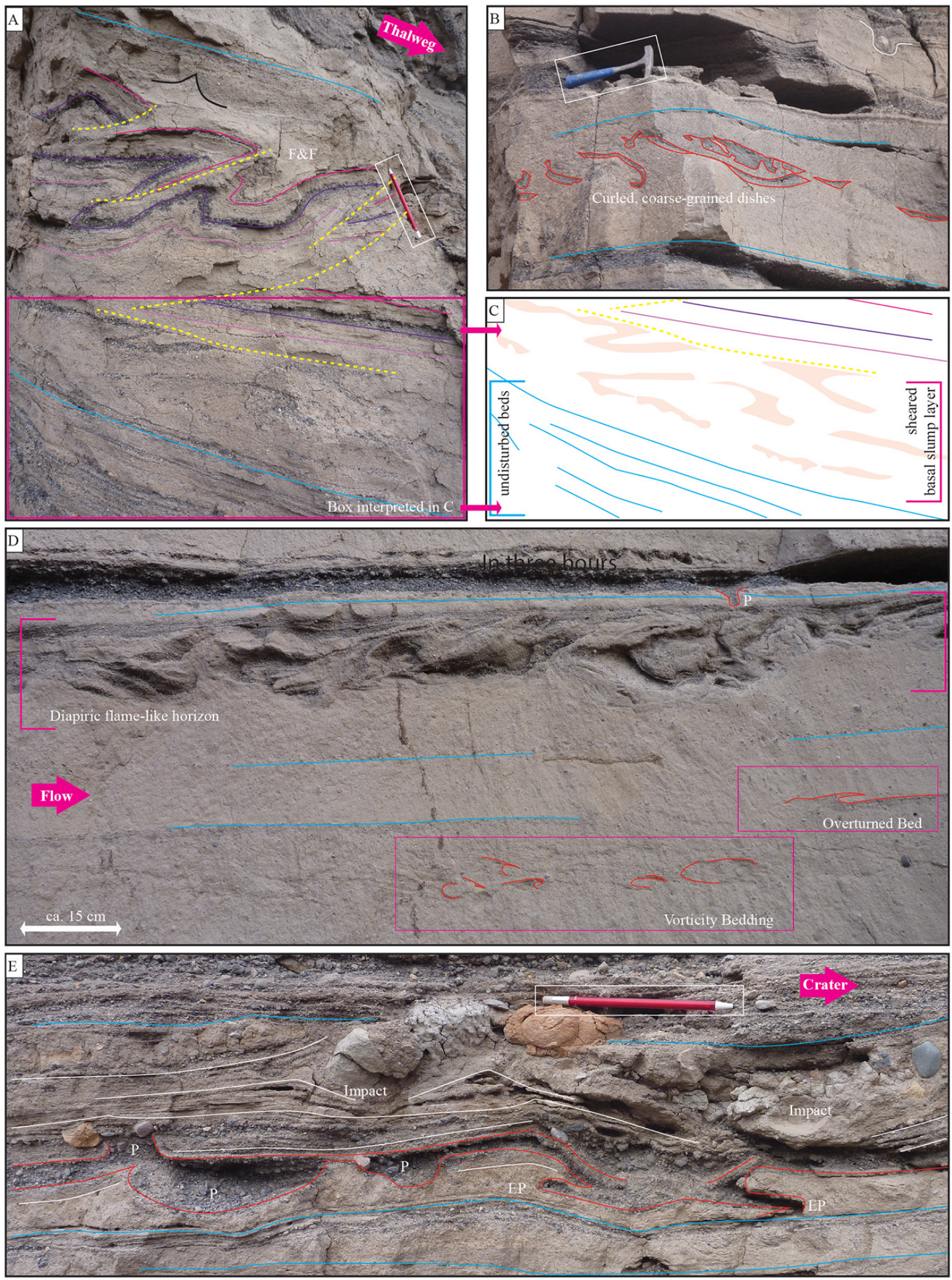

Figure 3. SSD structures from Ubehebe craters. (a) Folds-and-faults structure (F\&F) related to slump, with interpretation of the outlined lower part in (c). (b) Curled and pulled apart coarse-grained dishes interpreted as detached from the above. (d) Diapiric flame-like structures in upper part and a single downward-oriented, attached potatoid $(\mathrm{P})$, recumbent overturned bed in the middle right, vortex beds in the lower part. (e) Interpenetrating coarse bed with potatoids and elongate potatoids (EP) at the base of ballistic impact sags. 

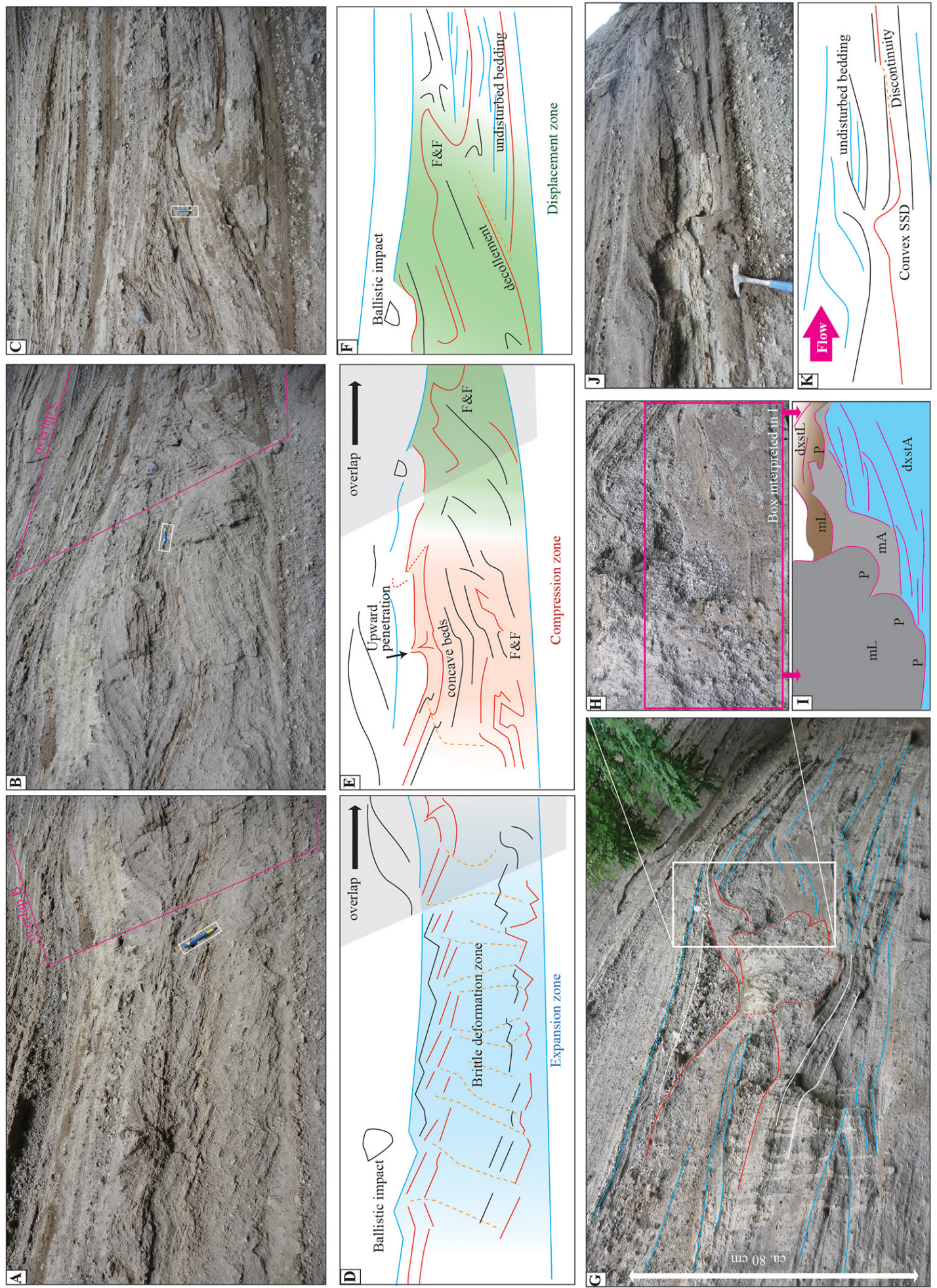

Figure 4. SSD structures from Laacher See. Panels (a-c) make a panorama of a composite structure due to impact interpreted in (d-f). Extensional tilted block (thrust dominos) dipping to the right in (a), compression due to impact in (b), and compressional displacement towards the right with folds-and-faults (F\&F) in (c) (image overlap dashed in gray). (g-i) Print of an impact resembling a pseudo "chute and pool" structure. Central compression is topped by lag breccia and rooted by massive lapilli (mL) potatoids $(\mathrm{P})$, themselves contoured by massive ash (mA) in otherwise diffusely cross-stratified ash and lapilli (dxstA, dxstL). Zoom in (h), with interpretation in (i). In (j and $\mathbf{k})$, a solitary symmetrical convex SSD resembling an anticline is contained in a fine grained fall layer and is related to dynamic pore pressure drop by subsequent flows. 


\section{Discussion and interpretation}

As a general observation, many of the examples documented have a fine-grained underlying or basal layer (Purrumbete, Laacher See, Ubehebe, Merapi). Fine-grained layers are likely to have distinct rheological properties that account for initiation of deformation (Mills, 1983). Ash is no exemption, at both small (Gibert et al., 2011) and regional scales (Wiemer, 2014, and references therein). Fine deposits are likely to have low permeability, impacting either on the transfer and diffusion of dynamic pore pressure from subsequent flows (Roche et al., 2013), or on fluid escapes from enclosed layers (Peltier et al., 2012).

\subsection{Influence of dynamic pore pressure}

SSDs from Soufrière Hills seem to originate from the dark mLA lensoidal layer that connects to the small basal attached potatoids and intrusions to the overlying pipes (Fig. 1a-b). Komorowski et al. (2013) interpreted similar features in the deposits of the Merapi 2010 block and ash flows as small degassing pipes related to rapidly deposited and fluidized flows. Here, the dark mLA layer is interpreted as fluidized and overpressurized in dynamic pore pressure during flow in order to explain the basal potatoids and intrusions as injection features. Basal dikes in subglacial deposits are indeed usually interpreted as indicating overpressure of the flows and injections (e.g., Douillet et al., 2012). The associated mLA layer would have held part of the overpressure through rapid sedimentation, and subsequently released the gas during deflation and compaction after burial by the overlying layer, further producing degassing pipes. This could also have destabilized the overlying beds and eased the formation of shear instabilities found at the upper interface of the $\mathrm{mA}$ layer above the pipes. Alternatively, the influence of bed-water turned into steam cannot be ruled out in the river thalweg. The large scale depletion of the surface (Fig. 1c) may relate to similar deflation of liquefied pockets, although simple re-arrangement of the grains underneath or any depletion could lead to similar surface expressions. The surface mainly consists of coarse particles and small deflation cracks developed; thus, the structure may relate to elutriation of fines.

The convex deformation of the fine-grained planar strata at Laacher See (Fig. 4j-k) lacks any recumbent component, is isolated, and no impact is visible. A localized decrease of the dynamic pore pressure of subsequent flows may have been transferred to the ground and slightly deformed the fine bed by suction. The deformed layer would have acted as a comparatively impermeable seal, containing the underpressure above it and lifting up. Negative dynamic pore pressures are indeed recorded from experimental granular flows and PDCs and trigger remobilization (erosion) (Roche et al., 2013; Farin et al., 2014; Bernard et al., 2014). The influence of dynamic pore pressure in destabilizing the sediment bed may be of importance in all syn-flow SSD scenarios. Both over- or under- pressurization can occur, and may systematically relate to both flow unsteadiness and flow non-uniformity. In air-particles experiments, an underpressure is associated with dilation at a flow front, and is directly followed by overpressure (Roche et al., 2010). The dune bedform found just above the SSD may also have had some influence and produced a slight overweight. Aeolian dunes produce SSD on underlying beds, yet rather as load structures and in static settings (Chan and Bruhn, 2014).

\subsection{Deformation driven by shearing of subsequent flows}

\subsubsection{Granular shear and pseudo Kelvin-Helmholz instabilities}

At Tungurahua, the imbrication of overturned laminae with confinement within an otherwise undeformed bed set suggests syn-depositional processes (Fig. 2). SSD cannot be correlated with any impact sag. The orientation parallel to the direction of the flow suggests the influence of the latter. The vortex-shaped SSD structures are interpreted as granular shear instabilities related to Kelvin-Helmholtz vortices, based on reports and interpretations from analogue experiments (Rowley et al., 2011; Farin et al., 2014). If a pure wind BBL had moved the sediments, they would have begun to saltate as individual grains rather than deform as a whole (Douillet et al., 2014), and since the deposits were dry, no water can have caused cohesion. Roche et al. (2013) explains the formation of wave instabilities at the interface between a fine-grained erodible bed and granular flow as linked with movements as a whole related to fluidization. This suggests that the observed features are indicative of a granular BBL and possible occurrence of traction carpets on the lee of the dune bedform. Although cross-stratification is generally interpreted as indicative of low particle concentration at the BBL, experiments by Leclair and Arnott (2005) have shown that laminations can be produced at more than $35 \%$ particle concentration, a concentration at which a granular BBL can occur. The scale of the structures being similar to experimental results, the granular BBL is interpreted to be of the same order of thickness and velocities (few centimeters thick and a few centimeters thick and a few meters per second velocity).

The downflow evolution of SSD at Tungurahua (Fig. 2c-d) brings further support to the discussion of Rowley et al. (2011). Indeed, they suggested that pseudo KelvinHelmholtz vortices may only be cryptic (hidden) in sedimentary records, since they intrinsically mix the deposits and create graded massive units. In the outcrop, well defined and thin lamination is visible downstream of the deformation front highlighted by vortices. In contrast, upstream from the front, stratification is comparatively thick and massive, with diffuse oversteepened laminations contained within 

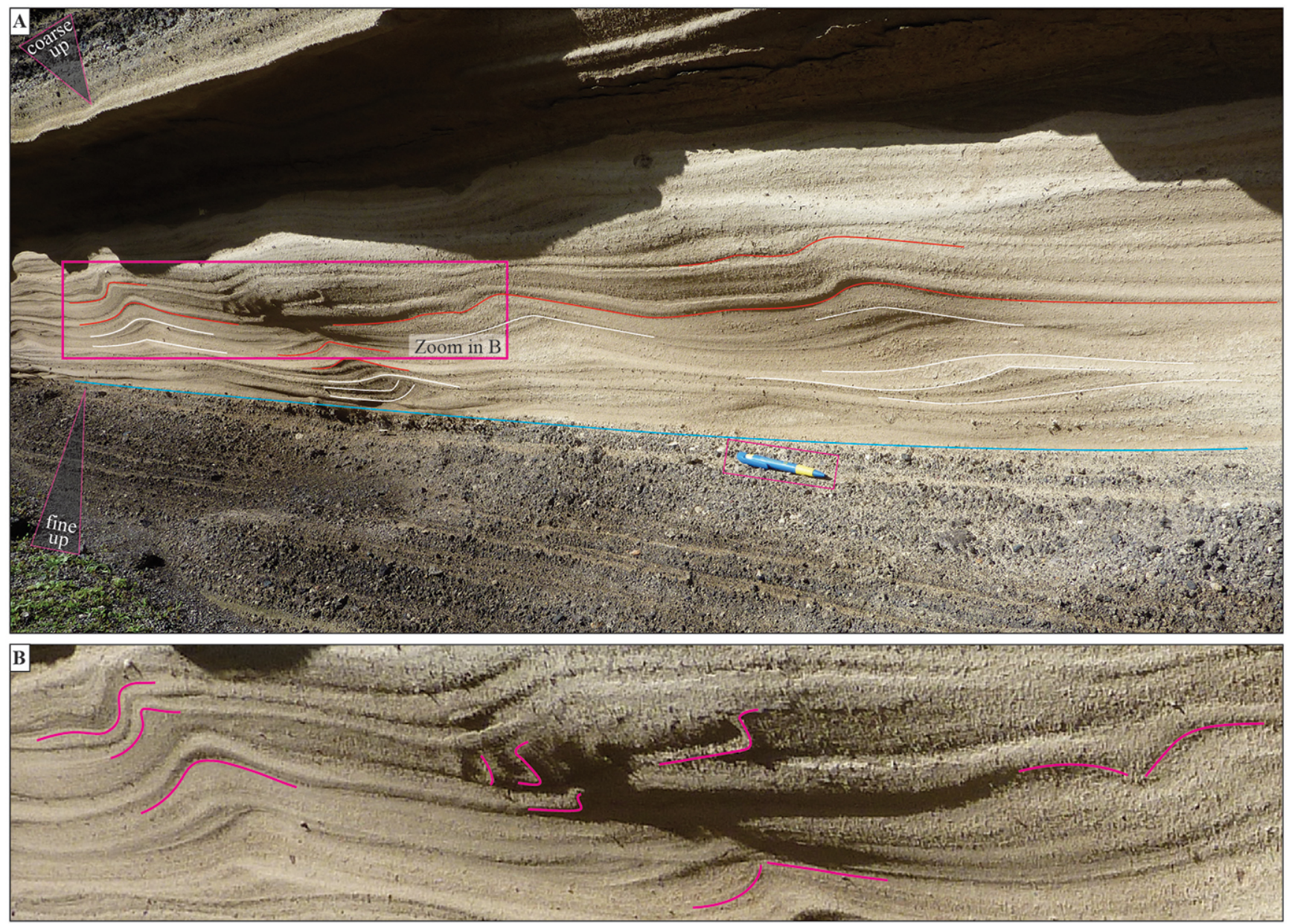

Figure 5. Tower Hill rim: (a) Train of slightly overturned and oversteepened laminations in fine ash bed sets with ripple cross-laminations related to shock waves at the vent. Triangles illustrate grading tendencies reflecting a transition from strombolian to phreatomagmatic explosions. (b) Zoom in oversteepened and slightly overturned beds.

the layers (Fig. 2d). This indicates the ploughing effect of the downstream migrating vortices that tend to mix and homogenize the initial bedding, as predicted by Rowley et al. (2011).

The recumbent and vortex structures at Ubehebe (Fig. 3d) have an overturning orientation with flow and a vortex shape. They only differ from Tungurahua by their occurrence in otherwise massive deposits. This may be an effect of successive ploughing by Kelvin-Helmholtz vortices or simply result from massive deposition. A vortex form is also observed at Soufrière Hills (Fig. 1b, top). In this case, the vortex is followed downstream by a gentle undulation and a steep step. Although the second and third structures have not a vortex shape, they are interpreted as proto, granular Kelvin-Helmholtz instabilities at different development stages. Moreover, the downstream repetition of deformation is taken as sign of the wavy nature of the instability.
Interestingly, sheared structure with a vortex-like structure are also present on the stoss and crest of dune bedforms covered by aggrading bed sets at Roccamonfina volcano (Italy, Figure 5 in Giannetti and Luongo, 1994). If all these structures represent granular Kelvin-Helmholtz instabilities, they could share similar dynamics to their fluid analogue and quantitative information could be derived (Rowley et al., 2011, developed in Appendix). From theoretical considerations, BBL velocities of more than $2.5 \mathrm{~m} \mathrm{~s}^{-1}$ for $1 \%$ relative particle concentration are necessary for instabilities to develop (Appendix, Fig. A1). This number rapidly drops for higher flow concentrations, and shear instabilities thus plausibly develop for basal granular BBL a few centimeters in thickness. 

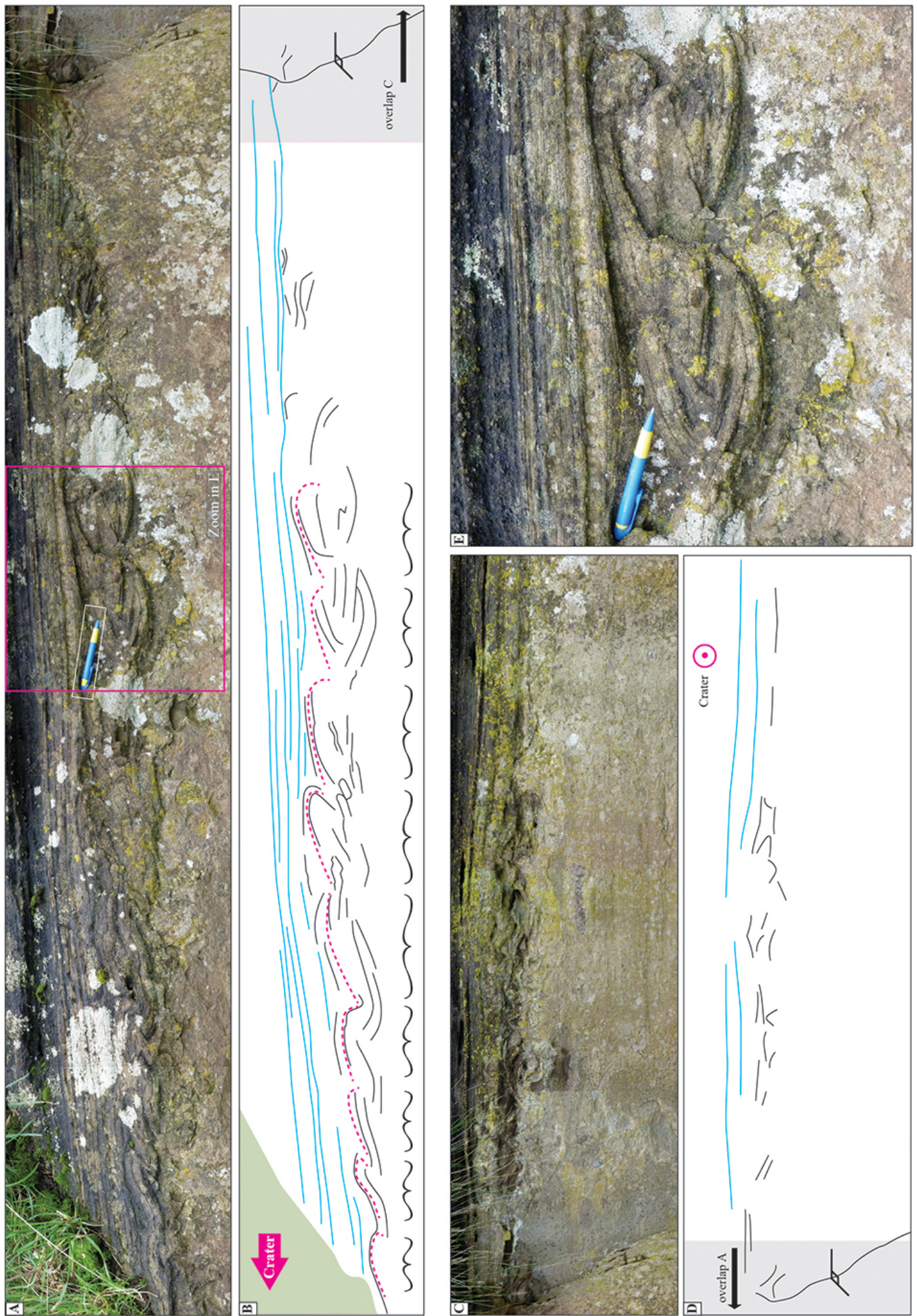

Figure 6. SSD at Purrumbete rim interpreted as related to shock waves. (a) Outcrop part oriented outward crater showing folds-and-faults with (b) interpretation; pink dashed lines highlight a pseudo recurrence and brackets a pseudo wavelength. Shaded zones indicates the overlap with (c), the outcrop part oriented parallel to rim showing chaotic, diapiric flame-like structures with (d) interpretation. (e) Zoom into recumbent folds-and-faults structures with overlying planar lamination (location outlined in a). 


\subsection{Deformation driven by gravity}

\subsubsection{Slumps}

For the Ubehebe thrusting folds-and-faults (Fig. 3a, top), observations point toward a gravitational slump: (1) deformed beds confined between undeformed strata; (2) large number of beds involved; (3) overturn orientation toward the thalweg of a channel; (4) axial planes of folds dipping upslope with folds' strike normal to microfaults; (5) imbrications and overlap (stacking) of deformed layers. The base of the folds-and-faults (Fig. 3a, base, and 3c) shows components of rotation, mixing and layer pull apart, indicating the floor thrust of slumping. Given the coherent state of the beds involved combined with their great variations in grain size and the thickness of SSD, a subaerial slump of wet sediment is favored. This would enhance cohesion on one hand, and the overweight due to water acting on freshly emplaced, unstable beds could also have triggered the sliding. The interpretation is further supported by the characteristics of the nearby ballistic impact sags. Overlying strata are not deformed and so the slump has occurred during or between eruptive phases.

\subsubsection{Granular Rayleigh-Taylor instabilities}

The diapiric flame-like structures at Ubehebe (Fig. 3d) are remarkably similar to structures produced by granular Rayleigh-Taylor instabilities between a granular medium and air (Niebling et al., 2010). Usual interpretations of such features point toward liquefaction, loading, or water escape structures (e.g., Owen, 1996b), a situation prone to occur during the eruption with high sedimentation rate and wet deposits. These explanations correspond to forms of granular Rayleigh-Taylor instabilities (Selker, 1993; Vinningland et al., 2007, 2010). Some of the flame-like structures are overturned toward the flow direction, which may indicate shearing and syn-PDC SSD. Asymmetrical features in turbidites were described by Moretti et al. (2001). They interpreted these as recording the paleo-slope and possibly paleo-flow direction, and made calculations to derive time-scales of deformations.

The curled and pulled apart, coarse-grained, isolated, flat dishes from Ubehebe (Fig. 3b) are interpreted as detached load casts. These form in the presence of an inverse density gradient resulting from changes of porosity driven by the grain size distribution of successive layers (Mills, 1983; Bridge and Demicco, 2008, p. 353-354), or when an underlying layer is fluidized (Nichols et al., 1994). In both cases, these also share the configuration for granular Rayleigh-Taylor instabilities (Nichols et al., 1994). A shock (seismicity or impact) may trigger detachment, but it is not necessary, and those structures may be post-eruptive. Their localized nature is taken to rule out remote triggers such as seismicity and no subsequent impact is visible above the structures. Further dynamic considerations coupled with the pseudo wavelength of the structures and interface characteristics may resolve the question of their similarity with Rayleigh-Taylor instabilities (see Selker, 1993, and Appendix).

\subsection{Deformation driven by ballistic impacts}

\subsubsection{Impact records}

At Laacher See, the tilted blocks (or domino/bookshelf structures) and thrust folds-and-faults packages locally share characteristics with slump folds (Fig. 4a-f). However, the very limited throw, absence of significant slope or possible slump trigger and the nested nature appear to exclude this interpretation. Given the great thickness of the disturbed beds, a surface instability, simple shearing or granular Kelvin-Helmholtz instability, also seems unlikely.

Yet, there is a preferential orientation directed roughly outward from the postulated vent. The lateral evolution of the SSD leads to another insight. (1) The upstream part dominated by tilted blocks indicates extension (Fig. 4a, 4d). (2) The central part with the concave shape of the upper beds together with upward-penetrating flame-like beds suggest vertical compression (Fig. 4b, 4e). (3) The folds-and-faults and local decollement in the downstream part record lateral displacement away from the central part ("escape zone", Fig. 4c, 4f). The source of the SSD can thus be localized above the central part, in the vertical compression zone, and with forced local displacement to the right. In light of this, the SSD is interpreted as the print of a large block bouncing on the bed and transmitting a deformation oriented with its trajectory. This is further supported by the presence of large blocks ( $>3 \mathrm{~m}$ diam.) in nearby areas in deposits otherwise dominated by ash and lapilli. Noteworthy, the abrupt confinement of the deformation in depth indicates a higher state of compaction of the undeformed beds, and thus their belonging to an older event separated by sufficiently long time for compaction. The basal ash layer would represent an initial fall event belonging to the deformed unit. Thus impact sags may also be used to trace genetic units.

The diagnosis is easier at Ubehebe (Fig. 3e), where impacting blocks are nested in deformed beds and just above potatoids. Thorough observation indicates that the coarse and massive layer escaped into the enclosing fine-grained beds: it is the most disturbed and exhibits potatoids with lateral and vertical spreading with respect to both the over and underlying layers, which still contain stratification. The isotropic nature of the leakage with apparent absence of preferential escape directions supports a liquefaction mechanism. To account for the coarse-grained nature, water saturation is inferred, in agreement with the other Ubehebe SSD structures. A grain-flow triggered by an impact-induced liquefaction of the porous and water-saturated coarse-ash 
enclosed in impermeable fine-grained layers has likely produced the nodules and dikes.

The pseudo "chute and pool" structure from Laacher See (Fig. 4g-i) shares similarities with both impact structures. The central part exhibits a depression with concave beds indicating compression. The right part is disturbed by massive lapilli material with downward-oriented potatoids (mL and $\mathrm{P}$ in Fig. $4 \mathrm{~h}-\mathrm{i})$. These are related to a liquefied grain flow of porous and water-saturated lapilli beds (sensu Owen and Moretti, 2011). The potatoids are underlined on the right by a ca. $10 \mathrm{~cm}$ thick, massive, ash-dominated contour with a diffuse front to the undisturbed cross-stratified bed sets ( $\mathrm{mA}$ and dxstA in Fig. 4i). The massive fore front is interpreted as representing the final escape of water that was less coupled with sediments. The liquefaction event is related to a large block impact that could have bounced and compacted the concave central depression. The extreme right of the structure containing stoss stratification dipping at more than the repose angle (upper part of Fig. 4h) may have been oversteepened by the rearrangement of the underlying sediment. Such a process was readily suggested by Nocita (1988), although the sediments of their study were later reinterpreted as fluvial rather than from PDCs (McPherson et al., 1989), without changing the accuracy of the process. The coarse lag breccia on top of the central depression may either indicate that the impacting block stayed in place and acted upon the depositional dynamics, resuspended fines during impact, or be a simple infill of the topography.

\subsubsection{A trigger for "chute and pool" structures?}

The two impact SSDs from Laacher See share remarkable similarities with the basal oversteepened truncations observed in structures generally interpreted as "chute and pool" structures (types I to IV of Schmincke et al., 1973). If the disturbed beds had been slightly more destabilized and permitted entrainment, the same configuration would be observed. Such impact SSDs would explain the oversteepened truncations and be at the origin of some of the "chute and pool" structures (see also Nocita, 1988). This would also explain the observation by Schmincke et al. (1973) that "chute and pool" structures occur in rather proximal parts, since ballistic blocks are likely to land closer to the crater than the total distance traveled by a PDC. This interpretation does not contradict the subsequent hydraulic jump dynamics of the structures, but the jump would be a consequence of the bed morphology rather than the other way round as usually suggested. A hydraulic jump would however not be necessary and simple morphological blocking of the bed load equally well explains the "chute and pool" depositional patterns (basal blocking and stop-and-go models in Douillet et al., 2013a; Martínez et al., 2007, resp.). The answer likely lies upstream from these structures, at the proximal truncation limit.

\subsection{Deformation driven by shock waves}

At Tower Hill (Fig. 5), the regularity of patterns, high degree of preservation and absence of slope appear to discredit slumping. The lateral persistence indicates a large-scale effect and discredit shear instabilities. Indeed, a flow with thin granular BBL forming pseudo Kelvin-Helmholtz instabilities is unlikely to stay in this state over several hundred meters. Moreover, either lateral flow velocities were slow enough for fine ash and volcanic dust with ripple lamination to deposit, or the ground was covered with a stretch of water. During the phreatomagmatic phase with efficient fragmentation associated with the fine beds, shock waves may have been produced by the explosions (e.g., Scolamacchia and Schouwenaars, 2009). These could propagate close to the rim, quaquaversal to the southern vent, and destabilize the fine-grained bed sets by transmitting their orientation to the ground. Valentine et al. (1989) suggested shock waves as a possible trigger for overturned flame-like structures. They noted that "when a shock passes over a granular deposit, bed particles experience a lift force due to the change in velocity across the shock" and "the bed immediately behind the shock has been observed in experiments to take on a wavelike configuration" citing the convincing experiments by Borisov et al. (1967). Recent shock experiments by Wayne et al. (2013) developed recumbent vortex-like shapes on dust beds and further support the interpretation (see also Fedorov, 2004).

The Purrumbete structure (Fig. 6) has a preferential direction away from crater: (1) all beds are overturned outside of the crater; (2) the deformation, vorticity degree and thickness of beds involved increase away from crater; whereas (3) the crater-parallel face is chaotic. Microfaults suggest cohesion, and there is neither evidence of traction nor of granular flow in the overlying planar deposits related to fallout; thus, granular shear is excluded. An envisaged interpretation is that these beds are involved in a small-scale slump. However, overlying beds lie conformably on top of the deformed strata, and are thus emplaced after deformation. This implies that a very small amount of material would be involved in a slump on an only gently sloping bed, unlikely to be sufficient to yield enough gravitational potential to initiate movement. The overturn, vorticity direction as well as the imbrication fabric at thrust faults would suggest an outward oriented slump, but no scar is visible at the deformation onset (left part). Rather, the evolution of intensity of deformation, absence of scar in the proximal side, and imbrication suggest that deformation could origin from the distal part, with some force pushing the sediment toward the crater. Similarly as for the Tower Hill maar, these structures can be the record of shock waves that destabilized the uppermost deposits and conferred them a tilt. Here again, the vortex-like entrainment evidenced in shock experiments supports the interpretation (Borisov et al., 1967; Wayne et al., 2013), and the proximity to the vent make shock wave influence probable. The 

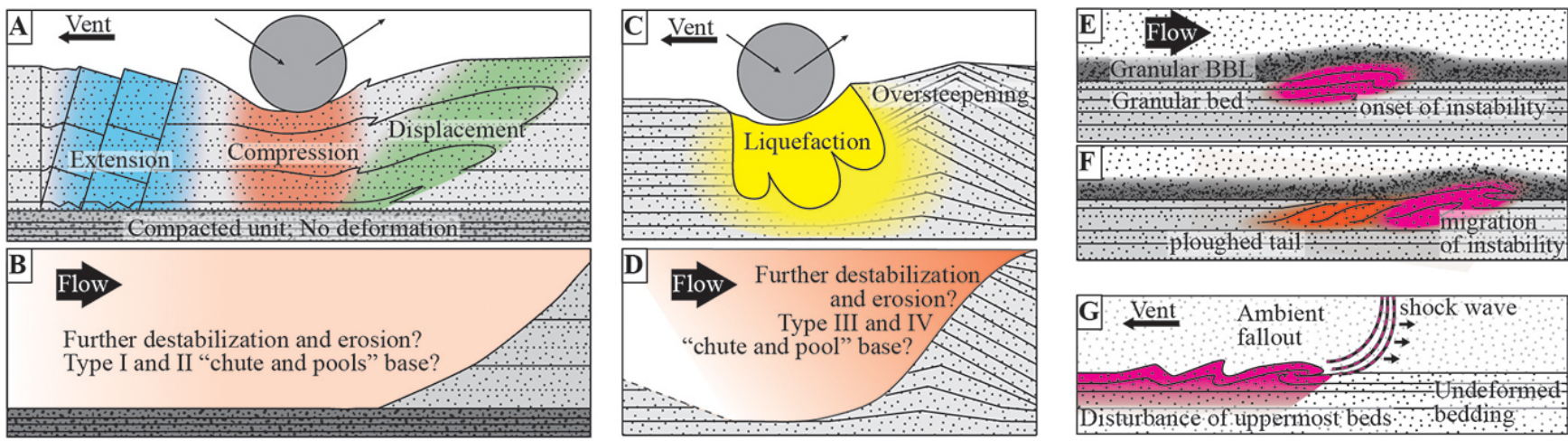

Figure 7. Interpretative sketch of syn-eruptive SSD. (a) and (c) SSD formed by ballistic impacts. Panels (b) and (d) show the envisaged scenario if destabilization of a and c permitted complete remobilization. These would form the base for types I and II "chute and pool" structures in Schmincke et al. (1973). (e) Formation of pseudo Kelvin Helmholtz instabilities between the bed and basal granular flow, and (f) the ploughing effect of a migrating instability. (g) Destabilization by shock waves.

passage of a shock wave would not be associated with direct sedimentation and here, the conformity of overlying fall beds supports a trigger mechanism without sedimentation. Indeed the signature is uniquely present as deformation. As SSD triggered by shock waves, these can share similarities with Richtmyer-Meshkov instabilities, the interaction of a shock wave with the interface between two fluids (Brouillette, 2002).

\section{Conclusions}

The exercise presented here has demonstrated the richness of information contained in SSD structures from the dilute PDC environment. SSD contains a record of syn-flow and syn-eruptive processes combined with post-depositional bedstate information.

Syn-flow processes were evidenced through granular, pseudo Kelvin-Helmholtz instabilities as well as evidences of suction and injection related to dynamic pore pressure of the flows. These observations feed the understanding of BBL processes of PDCs. Basal intrusions support the interpretation of fluidized flows with dynamic pore overpressure. Vortex-shaped laminae may be a valid indicator of granular-based flows or traction carpets. The suction vs. injection at the base of flows likely relate to changes in pore-pressure of the flow, and thus inform on its inhomogeneity.
Several syn-eruptive processes are recorded by SSD. Ballistic impacts may take more evolved forms than simple sags. They yield information on the bed state such as the compaction degree and water content, which helps to delimit eruptive units and environmental context. Some forms of impact may be at the origin of the so-called "chute and pool" bedforms. Slumps similarly inform on water content and eruptive units. The understanding of prevailing eruption type (wet vs. dry eruptions) may thus benefit from thorough analysis of SSD. Finally, we suggest that shock waves may leave a signature in the sediments by destabilization and overturning of the surface beds close to the vent without any direct deposits.

SSD from PDCs are of interest in the context of sedimentary research since they record subaerial, synand post-flow SSD structures, emphasizing that water is not a prerequisite for SSD. Moreover, PDC deposits can be unstable and have large permeability contrasts that facilitate SSD formation. Finally, the recognition of structures similar to instabilities occurring at fluid boundaries (Kelvin-Helmholz, Rayleigh-Tailor) further emphasizes the similarities between fluids and granular mixtures. SSD seems widespread in deposits of dilute PDCs, especially from phreatomagmatic eruptions, and should be addressed more attention. The variety of possible triggers, especially in the context of explosive volcanic eruptions, calls for further field and experimental work. 


\section{Appendix A: Instabilities between two fluids}

\section{A1 Granular Kelvin-Helmholtz instabilities at a bed-flow interface}

Given structures interpreted as granular Kelvin-Helmholtz instabilities, a theoretical resolution similar to the fluid instability can be expressed (Rowley et al., 2011). Any fluid dynamics analysis is based on the integration of "infinitesimal fluid elements", a notion comparable to grains in a granular mixture. The fluid-dynamics analytical method just justify in itself its applicability to granular mediums.

The problem is taken in 2-D with reference frame $\left(\boldsymbol{e}_{\boldsymbol{x}}\right.$ -flow parallel direction-, $\boldsymbol{e}_{z}$-upward direction parallel to $\boldsymbol{g}$, the gravity acceleration-). Consider two homogenous mediums $F_{1}$ and $F_{2}, F_{2}$ lying above $F_{1}$ and the interface an infinite horizontal plane. Suppose the fluids of densities $\rho_{1}$ and $\rho_{2}$ incompressible $\left(D \rho_{1,2} / D t=0\right)$, inviscid $(v=$ 0 ), with constant horizontal velocity $u_{1,2}(z)=U_{1,2} \boldsymbol{e}_{\boldsymbol{x}}$, and irrotational. The surface disturbance $(\xi)$ can be written in the form (see Drazin, 2002; Douillet, 2014, Chap. 2):

$\xi=\widetilde{\xi} \exp (i(k x)-s t)$

with $k$ being the wave number. Linearization of the problem posed by the boundary conditions has the following solution (see Drazin, 2002; Douillet, 2014, Chap. II.2):

$$
\begin{aligned}
& s=i k \frac{\rho_{1} U_{1}+\rho_{2} U_{2}}{\rho_{1}+\rho_{2}} \\
& \pm\left[\frac{k^{2} \rho_{1} \rho_{2}\left(U_{1}-U_{2}\right)^{2}}{\left(\rho_{1}+\rho_{2}\right)^{2}}-\frac{k g\left(\rho_{1}-\rho_{2}\right)}{\rho_{1}+\rho_{2}}\right]^{1 / 2} .
\end{aligned}
$$

Assumptions can be made for the case of an instability between a granular flow and deposit. The deposit does not move $\left(U_{1}=0\right)$, and the flow density is a portion of the deposit density $\left(\rho_{2}=x \rho_{1}\right.$ with $\left.0 \leq x \leq 1\right)$. Thus Eq. (A2) simplifies into

$$
s=i k U_{2} \frac{x}{1+x} \pm\left[k^{2} U_{2}^{2} \frac{x}{(1+x)^{2}}-k g \frac{(1-x)}{(1+x)}\right]^{1 / 2} .
$$

In order that a wave occurs, Eq. (A3) must have an imaginary component (the angular velocity $w=\operatorname{Im}(s)$ ). The second term in $s$ must be real for an exponential decay or increase to develop, and thus, be an instability. Thus the term under the square root must be positive and a condition for a bed-flow instability is (see also Rowley et al., 2011)

$U_{2}^{2}>\frac{g}{k} \frac{\left(1-x^{2}\right)}{x}$.

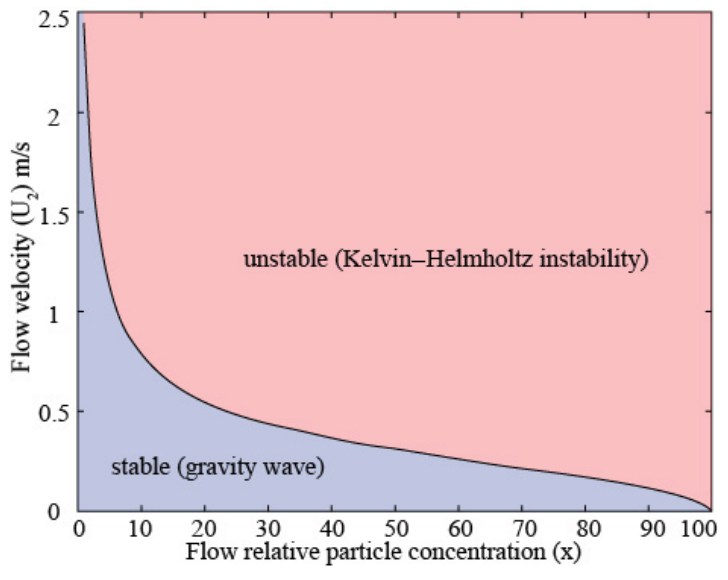

Figure A1. Threshold flow velocity $\left(U_{2}\right)$ as a function of flow's particle concentration compared to bed's particle concentration $(x)$ following Eq. (A4).

This condition is granted for large wave number $(k)$, i.e., short waves, high particle concentrations $(x)$, or large flow velocities (Fig. A1).

Further, the phase velocity of an instability $(c=w / k)$ can be derived

$c=\frac{x}{1+x} U_{2}$.

Under the assumptions, the wave velocity is thus entirely characterized by the concentration difference between the bed and flow $(x)$ and the velocity of the latter $\left(U_{2}\right)$, and the wavelength of the instability $(\lambda=2 \pi / k)$ does not appear explicitly.

\section{A2 Granular Rayleigh-Taylor instabilities}

A Rayleigh-Taylor instability is a surface instability between two resting fluids of different densities. Thus Eq. (A2) can be equally used with $U_{1,2}=0$. For the case of the curled and pulled-apart structures at Ubehebe (Fig. 3b), the upper coarse grained layer was sinking in the massive fine-grained layer underneath; thus $\rho_{2}=x \rho_{1}$ with $x \geq 1$, and Eq. (A2) simplifies into

$s= \pm\left[k g \frac{|1-x|}{1+x}\right]^{1 / 2}$.

The field observation is the length scale of the curled layers $(\lambda=2 \pi / k=$ ca. $15-30 \mathrm{~cm})$. The missing variables are a timescale for the growth of the instability and the density ratio. Estimating one permits to quantify the other. 
Acknowledgements. We are grateful to M. Heap for editing the manuscript. Useful comments from an anonymous reviewer together with comments and discussion with Massimo Moretti greatly contributed to the improvement of the manuscript. We are indebted to the following (partial) funding sources: the Bavarian grant THESIS (GAD), the German Deutsche Forschungsgemeinschaft grant KU2689/2-1 (GAD and UK), a Research Professorship (LMUexcellent) of the Bundesexzellenzinitiative and an advanced grant from the European Research Council-EVOKES (DBD).

Edited by: M. Heap

\section{References}

Allen, J. and Banks, N.: An interpretation and analysis of recumbent-folded deformed cross-bedding, Sedimentology, 19, 257-283, 1972.

Alsop, G. and Marco, S.: Soft-sediment deformation within seismogenic slumps of the Dead Sea Basin, J. Struct. Geol., 33, 433-457, 2011.

Alsop, G. I. and Marco, S.: Tsunami and seiche-triggered deformation within offshore sediments, Sediment. Geol., 261, 90-107, 2012.

Andrews, G. D. and Branney, M. J.: Emplacement and rheomorphic deformation of a large, lava-like rhyolitic ignimbrite: Grey's Landing, southern Idaho, Geol. Soc. Am. Bull., 123, 725-743, 2011.

Bernard, J., Kelfoun, K., Le Pennec, J.-L., and Vargas, S. V.: Pyroclastic flow erosion and bulking processes: comparing field-based vs. modeling results at Tungurahua volcano, Ecuador, B. Volcanol., 76, 1-16, 2014.

Borisov, A., Lyubimov, A., Kogarko, S., and Kozenko, V.: Instability of the surface of a granular medium behind sliding shock and detonation waves, Combust. Explo. Shock+, 3, 95-97, 1967.

Brand, B. D. and Clarke, A. B.: The architecture, eruptive history, and evolution of the Table Rock Complex, Oregon: From a Surtseyan to an energetic maar eruption, J. Volcanol. Geoth. Res., 180, 203-224, 2009.

Brand, B. D. and White, C. M.: Origin and stratigraphy of phreatomagmatic deposits at the Pleistocene Sinker Butte volcano, western Snake River Plain, Idaho, J. Volcanol. Geoth. Res., 160, 319-339, 2007.

Branney, M., Barry, T., and Godchaux, M.: Sheathfolds in rheomorphic ignimbrites, B. Volcanol., 66, 485-491, 2004.

Branney, M. J. and Kokelaar, B. P.: Pyroclastic density currents and the sedimentation of ignimbrites, Geo. Soc. Mem., 27, 143 pp., 2002.

Branney, M. J. and Kokelaar, P.: Volcanotectonic faulting, soft-state deformation, and rheomorphism of tuffs during development of a piecemeal caldera, English Lake District, Geol. Soc. Am. Bull., 106, 507-530, 1994.

Bridge, J. and Demicco, R.: Earth surface processes, landforms and sediment deposits, Cambridge University Press, 2008.

Brouillette, M.: The richtmyer-meshkov instability, Annu. Rev. Fluid Mech., 34, 445-468, 2002.
Brown, R. J., Orsi, G., and de Vita, S.: New insights into Late Pleistocene explosive volcanic activity and caldera formation on Ischia (southern Italy), B. Volcanol., 70, 583-603, 2008.

Caicedo-Carvajal, C. E., Glasser, B. J., and Shinbrot, T.: Granular flow transitions on sinusoidal surfaces, J. Fluid Mech., 556, 253 269, 2006.

Chan, M. A. and Bruhn, R. L.: Dynamic liquefaction of Jurassic sand dunes: processes, Origins, and implications, Earth Surf. Proc. Land., 39, 1478-1491, 2014.

Charbonnier, S. J. and Gertisser, R.: Field observations and surface characteristics of pristine block-and-ash flow deposits from the 2006 eruption of Merapi Volcano, Java, Indonesia, J. Volcanol. Geoth. Res., 177, 971-982, 2008.

Chen, J. and Lee, H. S.: Soft-sediment deformation structures in Cambrian siliciclastic and carbonate storm deposits (Shandong Province, China): Differential liquefaction and fluidization triggered by storm-wave loading, Sediment. Geol., 288, 81-94, 2013.

Conway, S. L., Shinbrot, T., and Glasser, B. J.: A Taylor vortex analogy in granular flows, Nature, 431, 433-437, 2004.

Crowe, B. M. and Fisher, R. V.: Sedimentary structures in basesurge deposits with special reference to cross-bedding, Ubehebe Craters, Death Valley, California, Geol. Soc. Am. Bull., 84, 663682, 1973.

Denis, M., Guiraud, M., Konaté, M., and Buoncristiani, J.-F.: Subglacial deformation and water-pressure cycles as a key for understanding ice stream dynamics: evidence from the Late Ordovician succession of the Djado Basin (Niger), Int. J. Earth Sci., 99, 1399-1425, 2010.

Doronzo, D. M. and Dellino, P.: Pyroclastic density currents and local topography as seen with the conveyer model, J. Volcanol. Geoth. Res., 278, 25-39, 2014.

Douillet, G., Ghienne, J.-F., Géraud, Y., Abueladas, A., Diraison, M., and Al-Zoubi, A.: Late Ordovician tunnel valleys in southern Jordan, Geol. Soc. Sp., 368, 275-292, 2012.

Douillet, G. A.: Flow and sedimentation from pyroclastic density currents. From large scale to boundary layer processes. PhD Dissertation, October 2014, Earth and Environmental Sciences, Ludwig Maximilian University, 2014.

Douillet, G. A., Pacheco, D. A., Kueppers, U., Letort, J., Tsang-HinSun, È., Bustillos, J., Hall, M., Ramón, P., and Dingwell, D. B.: Dune bedforms produced by dilute pyroclastic density currents from the August 2006 eruption of Tungurahua volcano, Ecuador, B. Volcanol., 75, 1-20, 2013a.

Douillet, G. A., Tsang-Hin-Sun, È., Kueppers, U., Letort, J., Pacheco, D. A., Goldstein, F., Von Aulock, F., Lavallée, Y., Hanson, J. B., Bustillos, J., et al.: Sedimentology and geomorphology of the deposits from the August 2006 pyroclastic density currents at Tungurahua volcano, Ecuador, B. Volcanol., 75, 1-21, 2013b.

Douillet, G. A., Rasmussen, K. R., Kueppers, U., Lo Castro, D., Merrison, J. P., Iversen, J. J., and Dingwell, D. B.: Saltation threshold for pyroclasts at various bedslopes: Wind tunnel measurements, J. Volcanol. Geoth. Res., 278, 14-24, 2014.

Drazin, P. G.: Introduction to hydrodynamic stability, Cambridge university press, 2002.

Ettensohn, F., Zhang, C., Gao, L., and Lierman, R.: Soft-sediment deformation in epicontinental carbonates as evidence of paleoseismicity with evidence for a possible new seismogenic 
indicator: Accordion folds, Sediment. Geol., 235, 222-233, 2011.

Farin, M., Mangeney, A., and Roche, O.: Fundamental changes of granular flow dynamics, deposition, and erosion processes at high slope angles: insights from laboratory experiments, J. Geophys. Res.-Earth, 119, 504-532, 2014.

Fedorov, A.: Mixing in wave processes propagating in gas mixtures (review), Combustion, Combust. Explo. Shock+, 40, 17-31, 2004.

Fiske, R. S.: Subaqueous pyroclastic flows in the Ohanapecosh Formation, Washington, Geol. Soc. Am. Bull., 74, 391-406, 1963.

Fiske, R. S. and Tobisch, O. T.: Paleogeographic significance of volcanic rocks of the Ritter Range pendant, central Sierra Nevada, California, Pacific Coast Paleogeography Symposium 2: Mesozoic Paleogeography of the Western United States, 391-406, 1978.

Forterre, Y. and Pouliquen, O.: Longitudinal vortices in granular flows, Phys. Rev. Lett., 86, 5886-5889, 2001.

Gençalioğlu-Kuşcu, G., Atilla, C., Cas, R. A., and Kuşcu, İ.: Base surge deposits, eruption history, and depositional processes of a wet phreatomagmatic volcano in Central Anatolia (Cora Maar), J. Volcanol. Geoth. Res., 159, 198-209, 2007.

Gernon, T., Fontana, G., Field, M., Sparks, R., Brown, R., and Mac Niocaill, C.: Pyroclastic flow deposits from a kimberlite eruption: the Orapa South Crater, Botswana, Lithos, 112, 566-578, 2009.

Gernon, T. M., Sparks, R. S. J., and Field, M.: Degassing structures in volcaniclastic kimberlite: examples from southern African kimberlite pipes, J. Volcanol. Geoth. Res., 174, 186-194, 2008.

Ghienne, J.-F.: Late Ordovician sedimentary environments, glacial cycles, and post-glacial transgression in the Taoudeni Basin, West Africa, Palaeogeogr. Palaeocl., 189, 117-145, 2003.

Giannetti, B. and Luongo, G.: Trachyandesite scoria-flow and associated trachyte pyroclastic flow and surge at Roccamonfina Volcano (Roman Region, Italy), J. Volcanol. Geoth. Res., 59, 313-334, 1994.

Gibert, L., Alfaro, P., García-Tortosa, F., and Scott, G.: Superposed deformed beds produced by single earthquakes (Tecopa Basin, California): Insights into paleoseismology, Sediment. Geol., 235, 148-159, 2011.

Goldfarb, D. J., Glasser, B. J., and Shinbrot, T.: Shear instabilities in granular flows, Nature, 415, 302-305, 2002.

Hall, M. L., Steele, A. L., Mothes, P. A., and Ruiz, M. C.: Pyroclastic density currents (PDC) of the 16-17 August 2006 eruptions of Tungurahua volcano, Ecuador: Geophysical registry and characteristics, J. Volcanol. Geoth. Res., 265, 78-93, 2013.

Jordan, S., Cas, R., and Hayman, P.: The origin of a large ( $>3 \mathrm{~km})$ maar volcano by coalescence of multiple shallow craters: Lake Purrumbete maar, southeastern Australia, J. Volcanol. Geoth. Res., 254, 5-22, 2013.

Kelfoun, K., Samaniego, P., Palacios, P., and Barba, D.: Testing the suitability of frictional behaviour for pyroclastic flow simulation by comparison with a well-constrained eruption at Tungurahua volcano (Ecuador), B. Volcanol., 71, 1057-1075, 2009.

Komorowski, J.-C., Jenkins, S., Baxter, P. J., Picquout, A., Lavigne, F., Charbonnier, S., Gertisser, R., Preece, K., Cholik, N., Budi-Santoso, A., et al.: Paroxysmal dome explosion during the Merapi 2010 eruption: Processes and facies relationships of associated high-energy pyroclastic density currents, J. Volcanol. Geoth. Res., 261, 260-294, 2013.

Leclair, S. F. and Arnott, R. W. C.: Parallel lamination formed by high-density turbidity currents, J. Sediment. Res., 75, 1-5, 2005.

Lowe, D. R.: Water escape structures in coarse-grained sediments, Sedimentology, 22, 157-204, 1975.

Mangeney, A., Roche, O., Hungr, O., Mangold, N., Faccanoni, G., and Lucas, A.: Erosion and mobility in granular collapse over sloping beds, J. Geophys. Res.-Earth, 115, F03040, doi:10.1029/2009JF001462, 2010.

Martínez, E., Pérez-Penichet, C., Sotolongo-Costa, O., Ramos, O., Måløy, K., Douady, S., and Altshuler, E.: Uphill solitary waves in granular flows, Phys. Rev. E,, 75, 031303, doi:10.1103/PhysRevE.75.031303, 2007.

Mattsson, H. B. and Tripoli, B. A.: Depositional characteristics and volcanic landforms in the Lake Natron-Engaruka monogenetic field, northern Tanzania, J. Volcanol. Geoth. Res., 203, 23-34, 2011.

McDonough, W. F., Waibel, A. F., and Gannet, M. W.: The re-interpretation of the Leone Lake sediments as a pyroclastic surge deposit and its tectonic significance, J. Volcanol. Geoth. Res., 20, 101-115, 1984.

McPherson, J., Flannery, J. R., and Self, S.: Discussion of -Soft-sediment deformation (fluid escape) features in a coarsegrained pyroclasticsurge deposit, north-central New Mexico-, Sedimentology, 36, 943-947, 1989.

Mills, P. C.: Genesis and diagnostic value of soft-sediment deformation structures?a review, Sediment. Geol., 35, 83-104, 1983.

Mohindra, R. and Bagati, T.: Seismically induced soft-sediment deformation structures (seismites) around Sumdo in the lower Spiti valley (Tethys Himalaya), Sediment. Geol., 101, 69-83, 1996.

Moretti, M., Soria, J. M., Alfaro, P., and Walsh, N.: Asymmetrical soft-sediment deformation structures triggered by rapid sedimentation in turbiditic deposits (Late Miocene, Guadix Basin, southern Spain), Facies, 44, 283-294, 2001.

Nichols, R., Sparks, R., and Wilson, C.: Experimental studies of the fluidization of layered sediments and the formation of fluid escape structures, Sedimentology, 41, 233-253, 1994.

Niebling, M. J., Flekkøy, E. G., Måløy, K. J., and Toussaint, R.: Sedimentation instabilities: impact of the fluid compressibility and viscosity, Phys. Rev. E, 82, 051302, doi:10.1103/PhysRevE.82.051302, 2010.

Nocita, B. W.: Soft-sediment deformation (fluid escape) features in a coarse-grained pyroclastic-surge deposit, north-central New Mexico, Sedimentology, 35, 275-285, 1988.

Odonne, F., Callot, P., Debroas, E.-J., Sempere, T., Hoareau, G., and Maillard, A.: Soft-sediment deformation from submarine sliding: Favourable conditions and triggering mechanisms in examples from the Eocene Sobrarbe delta (Ainsa, Spanish Pyrenees) and the mid-Cretaceous Ayabacas Formation (Andes of Peru), Sediment. Geol., 235, 234-248, 2011.

Owen, G.: Deformation processes in unconsolidated sands, Geol. Soc. Sp., 29, 11-24, 1987.

Owen, G.: Anatomy of a water-escape cusp in Upper Proterozoic Torridon Group sandstones, Scotland, Sediment. Geol., 103, 117-128, 1996a. 
Owen, G.: Experimental soft-sediment deformation: structures formed by the liquefaction of unconsolidated sands and some ancient examples, Sedimentology, 43, 279-293, 1996b.

Owen, G.: Load structures: gravity-driven sediment mobilization in the shallow subsurface, Geol. Soc. Sp., 216, 21-34, 2003.

Owen, G. and Moretti, M.: Determining the origin of soft-sediment deformation structures: a case study from Upper Carboniferous delta deposits in south-west Wales, UK, Terra Nova, 20, $237-$ 245, 2008

Owen, G. and Moretti, M.: Identifying triggers for liquefactioninduced soft-sediment deformation in sands, Sediment. Geol., 235, 141-147, 2011.

Owen, G., Moretti, M., and Alfaro, P.: Recognising triggers for soft-sediment deformation: current understanding and future directions, Sediment. Geol., 235, 133-140, 2011.

Peltier, A., Finizola, A., Douillet, G. A., Brothelande, E., and Garaebiti, E.: tructure of an active volcano associated with a resurgent block inferred from thermal mapping: The Yasur-Yenkahe volcanic complex (Vanuatu), J. Volcanol. Geoth. Res., 243, 59-68, 2012.

Pisarska-Jamroży, M. and Weckwerth, P.: Soft-sediment deformation structures in a Pleistocene glaciolacustrine delta and their implications for the recognition of subenvironments in delta deposits, Sedimentology, 60, 637-665, 2013.

Pistolesi, M., Delle Donne, D., Pioli, L., Rosi, M., and Ripepe, M.: The 15 March 2007 explosive crisis at Stromboli volcano, Italy: assessing physical parameters through a multidisciplinary approach, J. Geophys. Res.-Sol. Ea., 116, doi:10.1029/2011JB008527, 2011

Prata, G.: Complex eruption style and deposit changes during the evolution of the late Pleistocene Tower Hill maar- scoria cone Volcanic Complex, Newer Volcanics Province, Victoria, Australia, Monash University Melbourne, 2012.

Prata, G. and Cas, R.: Cyclicity in Fluctuating Phreatomagmatic and Magmatic Eruptive Styles at the $35 \mathrm{ka}$ Tower Hill Volcanic Complex, Southeast Australia, Geoscience Society of New Zealand Miscellaneous Publication 131A, p. 136, 2012.

Rawcliffe, H. J. and Brown, D. J.: Lithofacies architecture of basaltic andesite lavas and their interaction with wet-sediment: Part A - Chroinn, Kerrera, NW Scotland, Scot. J. Geol., 50, 49-55, 2014.

Roche, O., Montserrat, S., Niño, Y., and Tamburrino, A.: Pore fluid pressure and internal kinematics of gravitational laboratory air-particle flows: Insights into the emplacement dynamics of pyroclastic flows, Journal of Geophysical Research: Solid Earth (1978-2012), 115, 2010.

Roche, O., Niĩno, Y., Mangeney, A., Brand, B., Pollock, N., and Valentine, G. A.: Dynamic pore-pressure variations induce substrate erosion by pyroclastic flows, Geology, 41, 1170-1110, 2013

Røe, S.-L. and Hermansen, M.: New aspects of deformed cross-strata in fluvial sandstones: examples from Neoproterozoic formations in northern Norway, Sediment. Geol., 186, 283-293, 2006.

Rowley, P. J.: Analogue modelling of pyroclastic density current deposition, Royal Holloway, University of London. Unpublished PhD thesis, 2010.
Rowley, P. J., Kokelaar, P., Menzies, M., and Waltham, D.: Shearderived mixing in dense granular flows, J. Sediment. Res., 81, 874-884, 2011.

Sasnett, P., Goehring, B. M., Christie-Blick, N., and Schaefer, J. M.: Do phreatomagmatic eruptions at Ubehebe Crater (Death Valley, California) relate to a wetter than present hydro-climate?, Geophys. Res. Lett., 39, 2012.

Schmincke, H.-U., Fisher, R. V., and Waters, A. C.: Antidune and chute and pool structures in the base surge deposits of the Laacher See area, Germany, Sedimentology, 20, 553-574, 1973.

Scolamacchia, T. and Schouwenaars, R.: High-speed impacts by ash particles in the 1982 eruption of El Chichon, Mexico, J. Geophys. Res.-Sol. Ea., 114, doi:10.1029/2008JB005848, 2009.

Selker, J. S.: Expressions for the formation of load casts in soft sediment, J. Sediment. Res., 63, 1149-1151, 1993.

Sherwood, J., Oyston, B., and Kershaw, A.: The age and contemporary environments of Tower Volcano, Southwest Victoria, Australia, Proceedings of the Royal Society of Victoria, 116, 69-76, 2004.

Smith, N. J. and Kokelaar, B. P.: Proximal record of the 273 ka Poris caldera-forming eruption, Las Cañadas, Tenerife, B. Volcanol., 75, 1-21, 2013.

Stinton, A. J., Cole, P. D., Stewart, R. C., Odbert, H. M., and Smith, P.: The 11 February 2010 partial dome collapse at Soufrière Hills Volcano, Montserrat, Geological Society, London, Memoirs, 39. 133-152, 2014.

Sulpizio, R. and Dellino, P.: Sedimentology, depositional mechanisms and pulsating behaviour of pyroclastic density currents, Dev. Volcano., 10, 57-96, 2008.

Valentine, G. A., Buesch, D. C., and Fisher, R. V.: Basal layered deposits of the Peach Springs Tuff, northwestern Arizona, USA, B. Volcanol., 51, 395-414, 1989.

Van Loon, A.: Soft-sediment deformation structures in siliciclastic sediments: an overview, Geologos, 15, 3-55, 2009.

Vazquez, J. A. and Ort, M. H.: Facies variation of eruption units produced by the passage of single pyroclastic surge currents, Hopi Buttes volcanic field, USA, J. Volcanol. Geoth. Res., 154, 222-236, 2006.

Vinningland, J. L., Johnsen, Ø., Flekkøy, E. G., Toussaint, R., and Måløy, K. J.: Granular rayleigh-taylor instability: Experiments and simulations, Phys. Rev. Lett., 99, 1149-1151, 2007.

Vinningland, J. L., Johnsen, Ø., Flekkøy, E. G., Toussaint, R., and Måløy, K. J.: Size invariance of the granular Rayleigh-Taylor instability, Phys. Rev. E, 81, 041308, doi:10.1103/PhysRevE.81.041308, 2010.

Voight, B., Janda, R., Douglass, P., et al.: Nature and mechanics of the Mount St Helens rockslide-avalanche of 18 May 1980 Geotechnique, 33, 243-273, 1983.

Wadge, G., Robertson, R., and Voight, B.: The Eruption of Soufriere Hills Volcano, Montserrat from 2000 to 2010, Geological Society of London, 2014.

Ward, S. N. and Day, S.: Particulate kinematic simulations of debris avalanches: interpretation of deposits and landslide seismic signals of Mount Saint Helens, 1980 May 18, Geophys. J. Int., 167, 991-1004, 2006.

Waters, A. C. and Fisher, R. V.: Base surges and their deposits: Capelinhos and Taal volcanoes, J. Geophys. Res., 76 , 5596-5614, 1971. 
Wayne, P. J., Vorobieff, P., Smyth, H., Bernard, T., Corbin, C., Maloney, A., Conroy, J., White, R., Anderson, M., Kumar, S., et al.: Shock-Driven Particle Transport Off Smooth and Rough Surfaces, J. Fluid. Eng.-T. ASME, 135, 061302, doi:10.1115/1.4023786, 2013.
Whelley, P. L., Jay, J., Calder, E., Pritchard, M., Cassidy, N., Alcaraz, S., and Pavez, A.: Post-depositional fracturing and subsidence of pumice flow deposits: Lascar Volcano, Chile, B. Volcanol., 74, 511-531, 2012.

Wiemer, G.: On the Role of volcanic ash in submarine landslide initiation processes, $\mathrm{PhD}$ dissertation, Fachbereich Geowissenschaften der Universitaet Bremen, 2014. 